www.nature.com/pj

\title{
Aromatic-ring-layered polymers composed of fluorene and xanthene
}

\author{
Jonas Alves Fernandes, Yasuhiro Morisaki and Yoshiki Chujo
}

Polymer Journal (2011) 43, 733-737; doi:10.1038/pj.2011.58

Keywords: aromatic-ring-layered polymers; conjugated polymers; fluorene; xanthene

\section{INTRODUCTION}

Conjugated polymers show intriguing properties such as electrical conductivity, ${ }^{1-4}$ electroluminescence ${ }^{5-9}$ and chemical-sensing ability. ${ }^{10-12}$ Synthesis of new conjugated polymers is an important subject in polymer chemistry as well as in material chemistry, owing to their potential applications in optoelectronic devices. Generally, $\pi$-electrons are delocalized throughout the conjugated polymer backbone comprising of $\mathrm{sp}$ - and/or $\mathrm{sp}^{2}$-carbons. Recently, extensive studies have been conducted on conjugated polymers featuring the incorporation of main group elements. Various unique orbit interactions exist between the main group elements and $\pi$-conjugated carbon frameworks, for example, $\sigma-\pi$ (or $\sigma^{\star}-\pi^{\star}$ ) conjugation ${ }^{13,14}$ for Si and $\mathrm{p}-\pi^{\star}$ conjugation $^{15-17}$ for B. Furthermore, the properties of a new class of conjugated polymers that show through-bond conjugation and through-space conjugation in a polymer chain have been investigated. Through-space conjugated polymers were prepared by incorporating pseudo-para- ${ }^{18-24}$ and pseudo-ortho-substituted ${ }^{25}$ [2.2] paracyclophane into the conjugated polymer backbone, and their optical and electrochemical properties have been investigated in detail. Recently, pseudo-geminal-substituted [2.2] paracyclophane was used for the synthesis of through-space conjugated polymers, in which the $\pi$-electron systems fully overlapped with each other and showed a large Stokes shift. ${ }^{26}$

Polymers comprising layered $\pi$-electron systems have also attracted much attention as novel functional polymers. ${ }^{27}$ We have previously reported a new synthetic strategy for constructing aromatic ringlayered structures in a polymer main chain by using xanthene or naphthalene as the scaffold. This approach makes it possible to layer various aromatic rings in a single polymer chain; for example, cyclophane-, ${ }^{28,29}$ oligothiophene- ${ }^{30}$ and anthracene-layered polymers $^{31}$ were synthesized. Expansion of the substrate scope and investigation of the newly developed aromatic ring-layered polymers are of importance in the field of the conjugated polymers. In this study, we used fluorene as the layered aromatic unit and xanthene as the scaffold. Fluorene compounds possess easy functionality, thermal stability and prominent emitting-property; thus, they are valuable emitters as well as molecular probes to determine the environment via fluorescence spectroscopy due to high-quantum efficiencies and clear vibrational spectra. The fluorene-layered polymers were synthesized by the Sonogashira-Hagihara coupling reaction. The synthetic procedure, characterization and optical properties of the polymers were investigated in detail.

\section{EXPERIMENTAL PROCEDURE}

\section{General experimental details}

${ }^{1} \mathrm{H}$ and ${ }^{13} \mathrm{C}$ NMR spectra were recorded on a JNM-EX400 instrument (Jeol, Tokyo, Japan) at 400 and $100 \mathrm{MHz}$, respectively. The chemical shift values were expressed relative to $\mathrm{Me}_{4} \mathrm{Si}$ as an internal standard. High-resolution mass spectra were obtained on a JMS-SX102A spectrometer (Jeol, Tokyo, Japan). Gel permeation chromatography was carried out on a Tosoh 8020 instrument (TSKgel G3000HXL column; Tosoh, Tokyo, Japan) using $\mathrm{CHCl}_{3}$ as an eluent after calibration with standard polystyrene samples. Recyclable preparative high-performance liquid chromatography was performed on a Model 918R (JAIGEL-2.5H and 3H columns; Japan Analytical Industry, Tokyo, Japan) using $\mathrm{CHCl}_{3}$ as an eluent. Ultraviolet-visible absorption spectra were obtained on a Shimadzu UV3600 spectrophotometer (Shimadzu, Kyoto, Japan). Photoluminescence spectra were obtained on a Horiba FluoroMax-4 luminescence spectrometer (Horiba, Kyoto, Japan). Cyclic voltammetry was carried out on a CV-50W electrochemical analyzer (BAS, Tokyo, Japan) in $\mathrm{CH}_{2} \mathrm{Cl}_{2}$ containing $0.1 \mathrm{M}$ of the sample and $0.1 \mathrm{M}$ of $\mathrm{NBu}_{4} \mathrm{ClO}_{4}$ with a glassy carbon-working electrode, a $\mathrm{Pt}$ counter electrode, a $\mathrm{Ag} / \mathrm{AgCl}\left(\mathrm{Ag} / \mathrm{Ag}^{+}\right)$ reference electrode and a ferrocene/ferrocenium $\left(\mathrm{Fc} / \mathrm{Fc}^{+}\right)$external reference. Analytical thin-layer chromatography was performed with silica gel 60 Merck $\mathrm{F}_{254}$ plates (Merck, Whitehouse, NJ, USA). Column chromatography was performed with Wakogel C-300 silica gel (Wako Pure Chemical Industries, Osaka, Japan). Elemental analyses were carried out on a vario MICRO elemental analyzer (Elementar Analysensysteme GmbH, Hanau, Germany).

\section{Materials}

$\mathrm{NEt}_{3}$ was purchased and purified by passage through purification column under $\mathrm{Ar}$ pressure. ${ }^{32}$ Dehydrated-grade toluene was purchased and used without further purification. $\mathrm{Pd}\left(\mathrm{PPh}_{3}\right)_{4}, \mathrm{CuI}$ and 2,7-diiodofluorene (2a) were 
obtained commercially, and used without further purification. 2,7-Di-tertbutyl-4,5-diethynyl-9,9-dimethylxanthene (1) was synthesized according to the literature's procedure. ${ }^{33}$ 2,7-Diiodo-9,9-dialkylfluorenes $(\mathbf{2 b}-\mathbf{d})$ were synthesized according to the literature's procedure, ${ }^{34}$ and the spectral data matched with the literatures values $\left(\mathbf{2 b},{ }^{34} \mathbf{2} \mathbf{c}^{35}\right.$ and $\left.\mathbf{2} \mathbf{d}^{36}\right)$. All reactions were performed under Ar atmosphere.

\section{Polymer synthesis}

Typical procedure is as follows. ${ }^{37}$ 2,7-Di-tert-butyl-4,5-diethynyl-9,9-dimethylxanthene (1) (57 mg, $0.15 \mathrm{mmol}), 2,7$-diiodofluorene (2a) $(45 \mathrm{mg}, 0.14 \mathrm{mmol})$, $\mathrm{Pd}\left(\mathrm{PPh}_{3}\right)_{4}(17 \mathrm{mg}, 0.015 \mathrm{mmol})$ and $\mathrm{CuI}(14 \mathrm{mg}, 0.07 \mathrm{mmol})$ were placed in a Pyrex tube equipped with a magnetic stirrer and a reflux condenser. The equipment was purged with Ar, followed by adding toluene $(3.0 \mathrm{ml})$ and $\mathrm{NEt}_{3}(1.0 \mathrm{ml})$. The reaction was carried out at $100^{\circ} \mathrm{C}$ for $48 \mathrm{~h}$. After cooling, the reaction mixture was filtered by Celite. The filtrate was diluted with $\mathrm{CHCl}_{3}$, and it was washed with aqueous $\mathrm{NH}_{4} \mathrm{OH}(25 \%, 50 \mathrm{ml})$, brine $(50 \mathrm{ml})$ and water (50 ml). The organic layer was dried over $\mathrm{MgSO}_{4}$. After removal of $\mathrm{MgSO}_{4}$, the organic layer was dried. The residue was dissolved in a small amount of $\mathrm{CHCl}_{3}$ and reprecipitated from a large amount of methanol to afford polymer $\mathbf{3 a}$ as a brown solid ( $37 \mathrm{mg}, 46 \%)$.

Polymer 3a (37 mg, 46\%). ${ }^{1} \mathrm{H}$ NMR $\left(\mathrm{CD}_{2} \mathrm{Cl}_{2}, 400 \mathrm{MHz}\right): \delta=1.32$ (br), 1.38 (br), 1.70 (br), 3.36 (br), 7.33 (br m), 7.49 (br m) p.p.m. ${ }^{13} \mathrm{C} \mathrm{NMR}\left(\mathrm{CD}_{2} \mathrm{Cl}_{2}\right.$, $100 \mathrm{MHz}) \delta=31.3,32.5,34(\mathrm{~m}), 36.4,85.8,93.8,111.1,119.2,120.9,121.8,128$ (m), 130 (m), 140.3, 142.7, 145 (m), 148.4 p.p.m.

Polymer $3 \mathbf{b}(68 \mathrm{mg}, 62 \%) .{ }^{1} \mathrm{H}$ NMR $\left(\mathrm{CD}_{2} \mathrm{Cl}_{2}, 400 \mathrm{MHz}\right): \delta=0.77$ (br), 1.06 (br), 1.42 (br) 1.72 (br), 2.00 (br), 7.00 (br), 7.22 (br), 7.5 (br m) p.p.m. ${ }^{13} \mathrm{C}$ NMR $\left(\mathrm{CD}_{2} \mathrm{Cl}_{2}, 100 \mathrm{MHz}\right) \delta=13.9,22.7,24.0,29.7,31(\mathrm{~m}), 34(\mathrm{~m}), 40.3,55.7$, 86.3, 94.0, 110.9, 120-131 (m), 140 (m), 145.9, 148.3, 150.5, 153.6 p.p.m.

Polymer 3c (97 mg, 82\%). ${ }^{1} \mathrm{H}$ NMR $\left(\mathrm{CD}_{2} \mathrm{Cl}_{2}, 400 \mathrm{MHz}\right): \delta=0.56$ (br), 0.76 (br m), 1.39 (br m), 1.7 (m), 2.03 (br m), 7.0-7.8 (br m) p.p.m. ${ }^{13} \mathrm{C}$ NMR $\left(\mathrm{CD}_{2} \mathrm{Cl}_{2}, 100 \mathrm{MHz}\right) \delta=10.3,14.1,23.0,28(\mathrm{~m}), 31.3,33-35(\mathrm{~m}), 55.4,86.1,94.0$, 111.0, 120.0, 121.4, 123.9, 127-131 (m), 139.7, 145.8, 148.2, 150.4, 153.4 p.p.m.

Polymer 3d (108 mg, 80\%). ${ }^{1} \mathrm{H}$ NMR $\left(\mathrm{CD}_{2} \mathrm{Cl}_{2}, 400 \mathrm{MHz}\right): \delta=0.85$ (br), 1.2 (br m), 1.41 (s), 1.7-2.1 (br m), 7.0-7.8 (br m) p.p.m. ${ }^{13} \mathrm{C}$ NMR $\left(\mathrm{CD}_{2} \mathrm{Cl}_{2}\right.$, $100 \mathrm{MHz}) \delta=14.0,22.8,24.2,30(\mathrm{~m}), 30-32(\mathrm{~m}), 34.6,40.3,55.4,86.1,94.5$, 111.0, 120.1, 123.8, 126-132 (m), 145.8, 148.4, 151.1 p.p.m.

\section{4,5-Bis(2-fluorenyl)-9,9-dimethylxanthene (4)}

4,5-Diethynyl-9,9-dimethylxanthene ${ }^{38}(65 \mathrm{mg}, 0.25 \mathrm{mmol}), 2$-iodofluorene $\mathrm{e}^{34}$ (300 mg, $1.02 \mathrm{mmol}), \mathrm{Pd}\left(\mathrm{PPh}_{3}\right)_{4}(29 \mathrm{mg}, 0.025 \mathrm{mmol})$ and $\mathrm{CuI}(95 \mathrm{mg}$, $0.50 \mathrm{mmol}$ ) were placed in a Pyrex flask equipped with a magnetic stirrer and a reflux condenser. The equipment was purged with $\mathrm{Ar}$, followed by adding toluene $(3.0 \mathrm{ml})$ and $\mathrm{NEt}_{3}(1.5 \mathrm{ml})$. The reaction was carried out at $80^{\circ} \mathrm{C}$ for $9 \mathrm{~h}$. After cooling, the reaction mixture was diluted with $\mathrm{CHCl}_{3}$ and filtered by Celite. The filtrate was diluted with $\mathrm{CHCl}_{3}$, and it was washed with aqueous $\mathrm{NH}_{4} \mathrm{OH}(25 \%, 25 \mathrm{ml})$, brine $(25 \mathrm{ml})$ and water $(25 \mathrm{ml})$. The organic layer was dried over $\mathrm{MgSO}_{4}$. After removal of $\mathrm{MgSO}_{4}$, the organic layer was dried. The residue was subjected to column chromatography on $\mathrm{SiO}_{2}$ with hexane/ $\mathrm{CHCl}_{3}\left(\mathrm{v} / \mathrm{v}=4: 1, R_{\mathrm{f}} 0.1\right)$ as an eluent. The obtained compound was purified by recrystallization from $\mathrm{CHCl}_{3}$ to obtain 4,5-bis(2-fluorenyl)-9,9-dimethylxanthene (4) (118 $\mathrm{mg}, 0.20 \mathrm{mmol}, 80 \%)$ as a colorless crystal.
${ }^{1} \mathrm{H}$ NMR $\left(\mathrm{CD}_{2} \mathrm{Cl}_{2}, 400 \mathrm{MHz}\right) \delta=1.67(\mathrm{~s}, 6 \mathrm{H}), 3.49(\mathrm{~s}, 4 \mathrm{H}), 7.14(\mathrm{t}, J=7.6 \mathrm{~Hz}$, $2 \mathrm{H}), 7.19(\mathrm{~m}, 4 \mathrm{H}), 7.24(\mathrm{t}, J=7.2 \mathrm{~Hz}, 2 \mathrm{H}), 7.30(\mathrm{~d}, J=7.6 \mathrm{~Hz}, 2 \mathrm{H}), 7.35(\mathrm{~m}$, $4 \mathrm{H}), 7.48(\mathrm{~m}, 6 \mathrm{H})$ p.p.m. ${ }^{13} \mathrm{C}$ NMR $\left(\mathrm{CD}_{2} \mathrm{Cl}_{2}, 100 \mathrm{MHz}\right) \delta=32.4,34.4,36.6$, 84.9, 94.7, 112.0, 119.4, 119.9, 121.1, 123.1, 124.8, 126.5, 126.7, 127.0, 128.1, 130.4, 130.6, 131.9, 140.6, 141.7, 143.1, 143.4, 150.3 p.p.m. High-resolution mass spectra (fast atom bombardment): $\mathrm{m} / \mathrm{z}$ calcd. for $\mathrm{C}_{45} \mathrm{H}_{30} \mathrm{O}\left(\mathrm{M}^{+}\right)$: 586.2297, found: 586.2306. Anal. calcd. for $\mathrm{C}_{45} \mathrm{H}_{30} \mathrm{O}$ : C 92.12; $\mathrm{H} 5.15$; O 2.73, found: C 92.01; H 5.15; 2.64 .

${ }^{1} \mathrm{H}$ and ${ }^{13} \mathrm{C}$ NMR spectra of 3a-d (Supplementary Figures S1-8) and 4 (Supplementary Figures S9 and 10) are shown in Supplementary Information.

\section{RESULTS AND DISCUSSION}

Our approach toward construction of the aromatic-ring-layered structure involves the use of a 2,7-di-tert-butyl-9,9-dimethylxanthene skeleton as the scaffold. The synthetic scheme for fluorene-layered polymers 3a-d is shown in Scheme 1. Treatment of 2,7-di-tert-butyl4,5-diethynyl-9,9-dimethylxanthene (1) and 2,7-diiodofluorenes (2a-d) in the presence of a catalytic amount of $\mathrm{Pd}\left(\mathrm{PPh}_{3}\right)_{4}$ and $\mathrm{CuI}$ yielded a crude polymer, which was purified by reprecipitation from a large amount of $\mathrm{MeOH}$ to obtain target polymers $\mathbf{3 a}-\mathbf{d}$ in moderateto-good yields in the form of an orange powder. The polymerization results are summarized in Table 1.

The obtained polymers possessed good solubility in common organic solvents such as $\mathrm{CHCl}_{3}, \mathrm{CH}_{2} \mathrm{Cl}_{2}$, tetrahydrofuran and toluene, which allows easy characterizations as well as easy film formation by spin-coating. Molecular weight measurements were performed by gel permeation chromatography in $\mathrm{CHCl}_{3}$ eluent using a calibration curve of polystyrene standards. For example, the number-average molecular weight $\left(M_{\mathrm{n}}\right)$ and the polydispersity $\left(M_{\mathrm{w}} / M_{\mathrm{n}}\right)$ of polymer 3d were found to be 2600 and 1.3, as listed in Table 1 (run 4). The structures of polymers were confirmed by ${ }^{1} \mathrm{H}$ and ${ }^{13} \mathrm{C} \mathrm{NMR}$ spectroscopy, and all spectra are shown in Supplementary Information. Figure 1 shows the ${ }^{1} \mathrm{H}$ and ${ }^{13} \mathrm{C}$ NMR spectra of polymer $3 \mathbf{d}$ in $\mathrm{CD}_{2} \mathrm{Cl}_{2}$ as a representative example. In the ${ }^{1} \mathrm{H}$ NMR spectrum, signals of the dodecyl, tert-butyl and methyl protons were observed in the range of $0.8-2.2$ p.p.m. Aromatic proton peaks appeared at around 7.5 p.p.m. In the ${ }^{13} \mathrm{C}$ NMR spectrum, typical signals for acetylenic carbons were found at 86.1 and 94.5 p.p.m.

To obtain the structural insight into the polymers, we synthesized model compound $\mathbf{4}$ and subjected it to the single crystal X-ray analysis (Figure 2 and Supplementary Figure S12, data are summarized in Supplementary Table S1). As shown in the top view (Figure 2), the torsion angles of the xanthene scaffold and two fluorene rings are $61.8(3)^{\circ}$ and $7.6(3)^{\circ}$, respectively. This result indicates that one fluorene ring and the xanthene scaffold are almost on the same plane to maintain the $\pi$-conjugation in the solid state. The distance between the 4-position and the 5-position of xanthene was found to be $4.65 \AA$, and that between the 2-positions of fluorene was found to
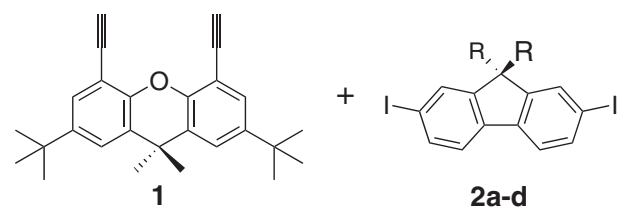
$\mathrm{Pd}\left(\mathrm{PPh}_{3}\right)_{4} / \mathrm{Cul}$
toluene, $\mathrm{Et}_{3} \mathrm{~N}$
$100{ }^{\circ} \mathrm{C}, 48 \mathrm{~h}$

a: $\mathrm{R}=\mathrm{H}$

b: $R=2$-ethylhexyl

c: $R=$ hexyl

d: $R=$ dodecyl

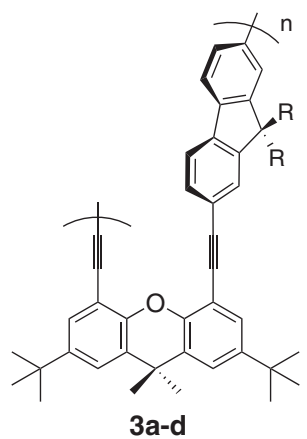

Scheme 1 Synthesis of polymers $3 a-d$. 


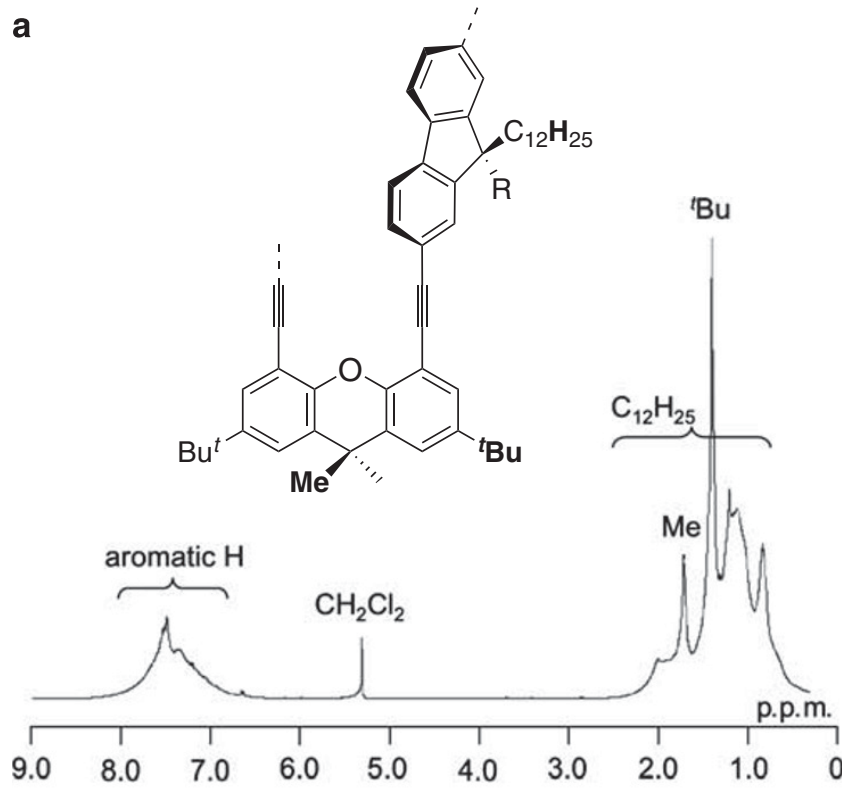

b

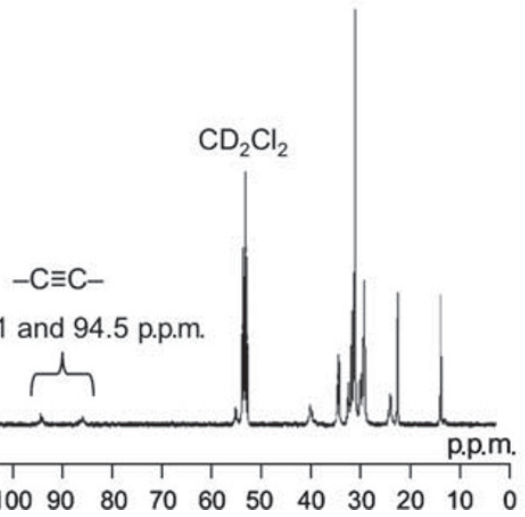

$16015014013012011010090 \quad 80 \quad 70 \quad 60 \quad 50 \quad 40 \quad 30 \quad 20 \quad 10 \quad 0$

Figure $1{ }^{1} \mathrm{H}$ and ${ }^{13} \mathrm{C}$ NMR spectra of polymer $3 \mathbf{d}$ in $\mathrm{CD}_{2} \mathrm{Cl}_{2}$.

Table 1 Results of polymerization

\begin{tabular}{llllll}
\hline Entry & Polymer & $-R$ & Yield $(\%)$ & $M_{n}{ }^{\mathrm{b}}$ & $M_{w} / M_{n}{ }^{\mathrm{b}}$ \\
\hline 1 & 3a & $-\mathrm{H}$ & 46 & 2000 & 1.1 \\
2 & 3b & $-\mathrm{C}_{6} \mathrm{H}_{13}$ & 62 & 1900 & 1.1 \\
3 & 3c & $-\mathrm{C}_{8} \mathrm{H}_{17}$ & 82 & 3100 & 1.3 \\
4 & 3d & $-\mathrm{C}_{12} \mathrm{H}_{25}$ & 80 & 2600 & 1.3 \\
\hline
\end{tabular}

Abbreviations: $M_{\mathrm{n}}$, number-average molecular weight; $M_{\mathrm{w}} / M_{\mathrm{n}}$, polydispersity.

alsolated yield.

bEstimated by gel permeation chromatography $\left(\mathrm{CHCl}_{3}\right)$ using polystyrene as standards.

be $4.89 \AA$. However, as shown in Figure 2, the shortest distance between two fluorene rings was approximately $3.5 \AA$, which is almost equal to the sum of the van der Waals radii of two $\mathrm{sp}^{2}$ carbon atoms (3.40 $\AA)$. The layered fluorene units seem to have sufficient space for twisting in the polymer backbone; a weak $\pi-\pi$ interaction among them in solution is expected. In the ${ }^{1} \mathrm{H}$ NMR spectra of polymer 3a and compound 4, signals of the $9-\mathrm{H}$ protons of the fluorene units appeared at $\delta=3.36$ and 3.49 p.p.m, respectively, (Supplementary Figure S11), which are upfield-shifted compared with the signal of fluorene itself ( $\delta=3.89$ p.p.m.) The $9-\mathrm{H}$ protons of $\mathbf{3 a}$ and 4 a

Front view

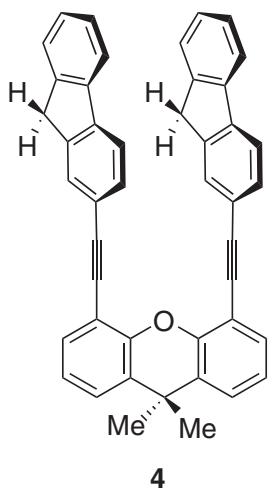

b

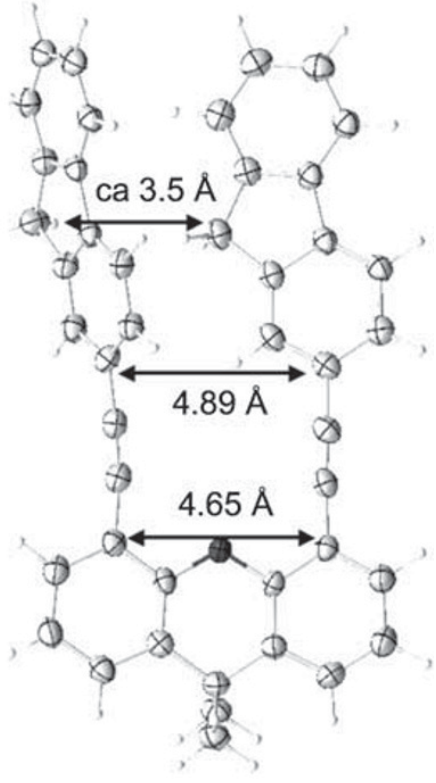

Top view

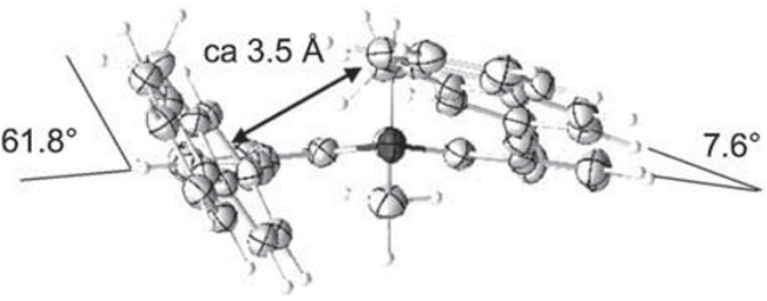

Figure 2 Structure of compound $\mathbf{4}$ and its ORTEP drawing. Thermal ellipsoids are drawn at the $50 \%$ probability level.

Table 2 Optical properties of polymers 3a-d

\begin{tabular}{lcccc}
\hline Entry & Polymer & $\lambda_{a b s, \max }{ }^{\mathrm{a}}(\mathrm{nm})$ & $\lambda_{P L, \max }{ }^{\mathrm{b}}(\mathrm{nm})$ & $\Phi_{P L^{\mathrm{c}}}$ \\
\hline 1 & 3a & 323 & 388,409 & 0.40 \\
2 & 3b & 335 & 390,411 & 0.50 \\
3 & 3c & 334 & 389,410 & 0.36 \\
4 & 3d & 348 & 392,414 & 0.28 \\
\hline
\end{tabular}

an $\mathrm{CHCl}_{3}, 1.0 \times 10^{-5} \mathrm{M}$

II $\mathrm{CHCl}_{3}, 1.0 \times 10^{-7} \mathrm{M}$, excited at each absorption maximum.

cAbsolute photoluminescence quantum efficiency.

have ring current effect of the neighboring fluorene units because of the twist motion of the fluorene units on the xanthene backbone.

The optical properties of polymers $\mathbf{3 a}-\mathbf{d}$ were examined, and the results are summarized in Table 2 . In addition, the normalized ultraviolet-visible absorption spectra of $\mathbf{3 a}-\mathbf{d}$ and 4 in $\mathrm{CHCl}_{3}\left(1.0 \times 10^{-5} \mathrm{M}\right)$ are shown in Figure 3a. The absorption maxima of 4 and the polymers were observed at around 315 and $350 \mathrm{~nm}$, respectively. The conjugation lengths of $\mathbf{3 a - d}$ were longer than that of 4 ; this is because 3a-d consist of 2,7-di-substituted fluorine, whereas 4 consists of 

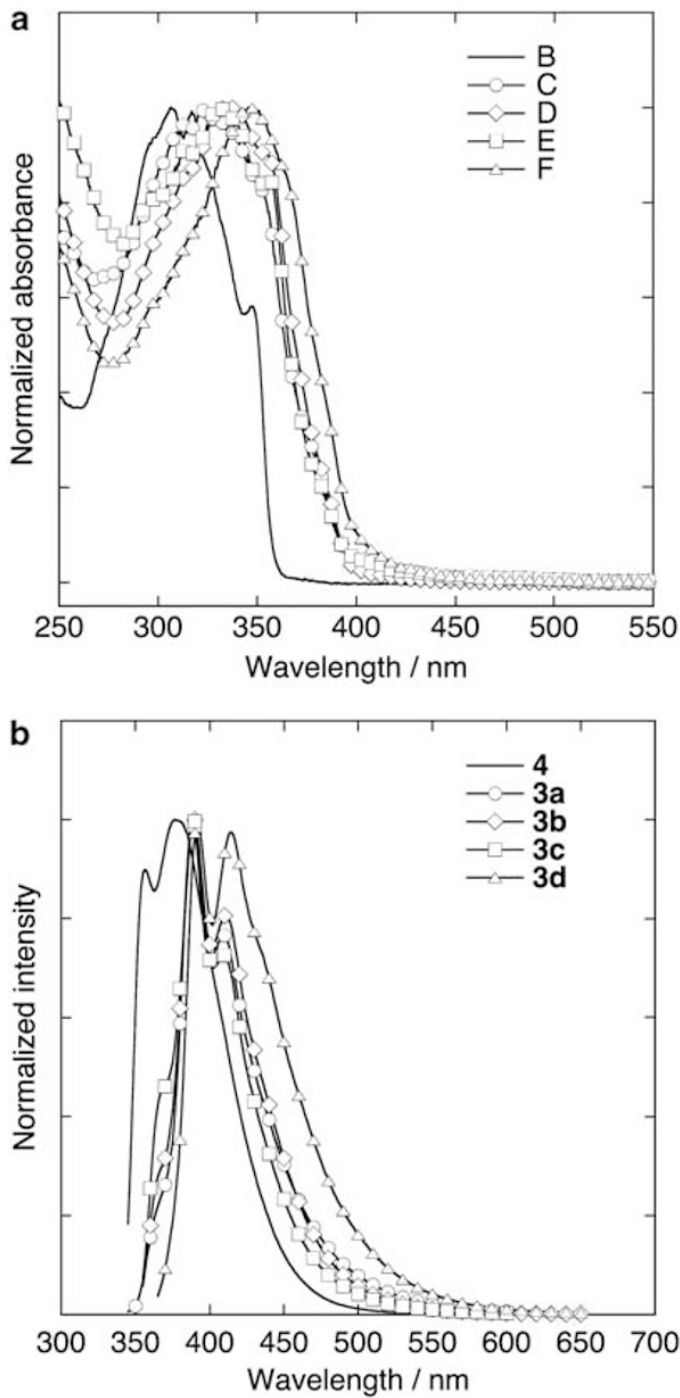

Figure 3 (a) Ultraviolet-visible absorption spectra in $\mathrm{CHCl}_{3}\left(1.0 \times 10^{-5} \mathrm{M}\right)$ and (b) photoluminescence spectra in $\mathrm{CHCl}_{3}\left(1.0 \times 10^{-7} \mathrm{M}\right.$, excited at absorption maxima) of polymers $\mathbf{3 a -} \mathbf{d}$ and $\mathbf{4}$.

monosubstituted fluorene. The absorption bands of $\mathbf{3 a} \mathbf{a}-\mathbf{d}$ are derived from the $S_{0}-S_{1}$ transition of 2,7-bis(arylethynyl)fluorene moieties.

Figure $3 \mathrm{~b}$ shows the photoluminescence spectra of $\mathbf{3 a - d}$ in dilute $\mathrm{CHCl}_{3}$ solutions $\left(1.0 \times 10^{-7} \mathrm{M}\right)$ excited at each absorption maximum. We confirmed that this concentration $\left(1.0 \times 10^{-7} \mathrm{M}\right)$ was sufficiently diluted so as to avoid intermolecular interactions among the polymer chains according to the concentration effect. The polymers emitted blue light in the visible range with peak maxima at around $400 \mathrm{~nm}$. The spectra indicated vibrational structures with absolute quantum efficiencies of $0.28-0.50$, ruling out excimer formation among the layered fluorene units in the polymer backbone. The $\pi-\pi$ interactions among the fluorene units in the polymer chain were weak in the ground and the excited states.

The electrochemical property of the polymers was examined by cyclic voltammetry. The typical cyclic voltammograms, shown in Figure 4, were obtained from a polymer 3d solution in $\mathrm{CH}_{2} \mathrm{Cl}_{2}$ containing $0.1 \mathrm{M} \mathrm{NBu}_{4} \mathrm{ClO}_{4}$ using a glassy carbon-working electrode, $\mathrm{Pt}$ counter electrode, $\mathrm{Ag} / \mathrm{Ag}^{+}$reference electrode and $\mathrm{Fc} / \mathrm{Fc}^{+}$external reference. As shown in Figure 4, polymer 3d was readily oxidized with

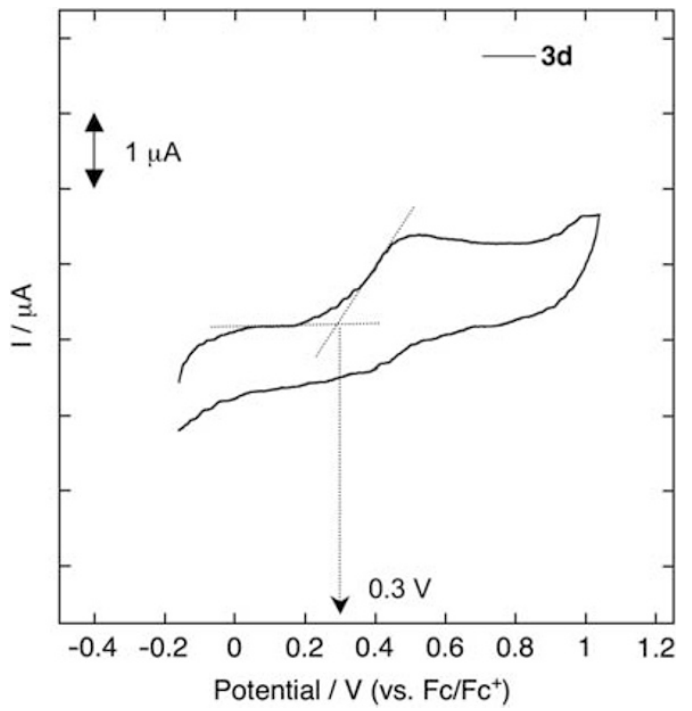

Figure 4 Cyclic voltammogram of polymer $3 \mathbf{d}$ in $\mathrm{CH}_{2} \mathrm{Cl}_{2}(0.1 \mathrm{~m})$ containing $\mathrm{NBu}_{4} \mathrm{ClO}_{4}(0.1 \mathrm{~m})$ using a glassy carbon-working electrode, a Pt counter electrode, a $\mathrm{Ag} / \mathrm{Ag}^{+}$reference electrode and ferrocene/ferrocenium $\left(\mathrm{Fc} / \mathrm{Fc}^{+}\right)$ as an external reference.

an oxidation potential $\left(E_{\text {onset }}\right)$ of approximately $0.30 \mathrm{~V}$ (vs $\mathrm{Fc} / \mathrm{Fc}^{+}$) (cyclic voltammetry measurement of $\mathbf{4}$ was carried out, and the voltammogram is shown in Supplementary Figure S13. The $E_{\text {onset }}$ of 4 appeared at around $0.13 \mathrm{~V}\left(\mathrm{vs} \mathrm{Fc}_{\mathrm{Fc}}{ }^{+}\right)$. The slight difference of the $E_{\text {onset }}$ values between the polymer and the model compound is probably derived from the number of the electron withdrawing carbon-carbon triple bonds of the fluorene unit.). The highest occupied molecular orbital energy level of the polymer was calculated to be approximately $-5.1 \mathrm{eV}$, and the lowest unoccupied molecular orbital level was estimated to be $-2.3 \mathrm{eV}$ according to the highest occupied molecular orbital-lowest unoccupied molecular orbital energy band gap obtained from the ultraviolet-visible absorption spectrum (These values were estimated from the $E_{\text {onset }}$ of the polymers and the energy level of $\mathrm{Fc} / \mathrm{Fc}^{+}(4.80 \mathrm{eV})$, namely highest occupied molecular orbital $=-4.80-E_{\text {onset. }}$. For example, see Pommerehne et al. $^{39}$ ).

In conclusion, we described the synthesis and properties of a new class of aromatic-ring-layered polymer comprising layered fluorene and a xanthene scaffold. The polymers can be prepared in moderateto-good yields by Sonogashira-Hagihara coupling. The polymers are soluble in common organic solvents and can be spin-coated into thin films from solution. We found that the $\pi-\pi$ interactions among the layered fluorene units in the polymer backbone are ineffective in the ground and the excited states; thus, the polymers emit without excimer formation, despite the layered structure. We intend to conduct further studies on the synthesis of various aromatic-ring-layered polymers and fabrication of optoelectronic devices such as light-emitting device and hole-transporting device, in which these polymers find application.

\section{ACKNOWLEDGEMENTS}

This work was supported by a Grant-in-Aid for Young Scientists (A) (No. 21685012) from the Ministry of Education, Culture, Sports, Science and Technology, Japan. The financial support from the Kansai Research Foundation of Technology Promotion was also acknowledged. 
1 Skotheim, T. A., Elsenbaumer, R. L. \& Reynolds, J. R. Eds. Handbook of Conducting Polymers, 3rd ed. (Marcel Dekker, New York, 2006).

2 Shirakawa, H. The discovery of polyacetylene film: the dawning of an era of conducting polymers. Angew. Chem., Int. Ed. Engl. 40, 2574-2580 (2001).

3 MacDiarmid, A. G. 'Synthetic metals': a novel role for organic polymers. Angew. Chem., Int. Ed. Engl. 40, 2581-2590 (2001).

4 Heeger, A. J. Semiconducting and metallic polymers: the fourth generation of polymeric materials. Angew. Chem., Int. Ed. Engl. 40, 2591-2611 (2001).

5 Kraft, A., Grimsdale, A. C. \& Holmes, A. B. Electroluminescent conjugated polymers-seeing polymers in a new light. Angew. Chem., Int. Ed. Engl. 37, 402-428 (1998)

6 Friend, R. H., Gymer, R. W., Holmes, A. B., Burroughes, J. H., Marks, R. N., Taliani, C., Bradley, D. D. C., Dos Santos, D. A., Bredas, J. L., Lögdlund, M. \& Salaneck, W. R. Electroluminescence in conjugated polymers. Nature 397, 121-128 (1999).

7 Mitschke, U. \& Bauerle, P. The electroluminescence of organic materials. J. Mater. Chem. 10, 1471-1507 (2000).

8 Bernius, M. T., Inbasekaran, M., O’Brien, J. \& Wu, W. Progress with light-emitting polymers. Adv. Mater. 121, 1737-1749 (2000).

9 Akcelrud, L. Electroluminescent polymers. Prog. Polym. Sci. 28, 875 (2003).

10 McQuade, D. T., Pullen, A. E. \& Swager, T. M. Conjugated polymer-based chemical sensors. Chem. Rev. 100, 2537-2574 (2000).

11 Juan, Z. \& Swager, T. M. Poly(arylene ethynylene)s in chemosensing and biosensing. Adv. Polym. Sci. 177, 151-179 (2005).

12 Swager, T. M. Semiconducting poly(arylene ethylene)s. in Acetylene Chemistry (eds. Diederich, F., Stang, P. J. \& Tykwinski, R. R.) 233-258 (Weinheim, Germany, 2005).

13 Zhan, X., Barlow, S. \& Marder, S. R. Substituent effects on the electronic structure of siloles. Chem. Commum. 1948-1955 (2009).

14 Yamaguchi, S. \& Tamao, K. Silole-containing $\sigma$ - and $\pi$-conjugated compounds. J. Chem. Soc., Dalton Trans. 3693-3702 (1998).

15 Nagai, A. \& Chujo, Y. Luminescent organoboron conjugated polymers. Chem. Lett. 39, 430-435 (2010).

16 Jäkle, F. Advances in the synthesis of organoborane polymers for optical, electronic, and sensory applications. Chem. Rev. 110, 3985-4220 (2010).

17 Yamaguchi, S. \& Wakamiya, A. Boron as a key component for new $\pi$-electron materials. Pure Appl. Chem. 78, 1413-1424 (2006).

18 Morisaki, Y. \& Chujo, Y. Synthesis of $\pi$-stacked polymers on the basis of [2.2] paracyclophane. Bull. Chem. Soc. Jpn. 82, 1070-1082 (2009).

19 Morisaki, Y. \& Chujo, Y. Cyclophane-containing polymers. Prog. Polym. Sci. 33, 346-364 (2008).

20 Morisaki, Y. \& Chujo, Y. Through-space conjugated polymers based on cyclophanes. Angew. Chem., Int. Ed. Engl. 45, 6430-6437 (2006).

21 Guyard, L., Audebert, P., Dolbier, W. R. Jr. \& Duan, J.- X. Synthesis and electrochemical polymerization of new oligothiophene functionalized fluorocyclophane. J. Electroanal. Chem. 537, 189-193 (2002)
22 Guyard, L. \& Audebert, P. Synthesis and electrochemical polymerization of bis-dithienyl cyclophane. Electrochem. Commun. 3, 164-167 (2001).

23 Salhi, F. \& Collard, D. M. $\pi$-stacked conjugated polymers: the influence of paracyclophane $\pi$-stackes on the redox and optical properties of a new class of broken conjugated polythiophenes. Adv. Mater. 15, 81-85 (2003).

24 Salhi, F., Lee, B., Metz, C., Bottomley, L. A. \& Collard, D. M. Influenece of $\pi$-stacking on the redox properties of oligothiophenes: ( $\alpha$-alkyloligo-thienyl)para[2.2]cyclophane. Org. Lett. 4, 3195-3198 (2002).

25 Morisaki, Y., Wada, N., Arita, M. \& Chujo, Y. Synthesis of through-space conjugated polymers containing the pseudo-ortho-linked [2.2]paracyclophane moiety. Polym. Bull. 62, 305-314 (2009)

26 Jagtap, S. P. \& Collard, D. M. Multitiered 2D $\pi$-stacked conjugated polymers based on pseudo-geminal disubstituted [2.2]paracyclophane. J. Am. Chem. Soc. 135, 12208-12209 (2010)

27 Nakano, T. Synthesis, structure and function of $\pi$-stacked polymers. Polym. J. 42, 103-123 (2010).

28 Morisaki, Y., Murakami, T. \& Chujo, Y. Synthesis and properties of [2.2]paracyclophanelayered polymers. Macromolecules 41, 5960-5963 (2008).

29 Morisaki, Y., Murakami, T., Sawamura, T. \& Chujo, Y. [2.2]Paracyclophane-layered polymers end-capped with fluorescence quenchers. Macromolecules 42, 3656-3660 (2009).

30 Morisaki, Y., Fernandes, J. A. \& Chujo, Y. Synthesis of oligothiophene-layered polymers. Macromol. Rapid Commun. 30, 2107-2111 (2009).

31 Morisaki, Y., Sawamura, T., Murakami, T. \& Chujo, Y. Synthesis of anthracene-stacked oligomers and polymer. Org. Lett. 12, 3188-3191 (2010).

32 Pangborn, A. B., Giardello, M. A., Grubbs, R. H., Rosen, R. K. \& Timmers, F. J. Safe and convenient procedure for solvent purification. Organometallics 15, 1518-1520 (1996).

33 Morisaki, Y., Fernandes, J. A., Wada, N. \& Chujo, Y. Synthesis and properties of carbazole-layered polymers. J. Polym. Sci., Part A: Polym. Chem. 47, 4279-4288 (2009).

34 Lee, S. H., Nakamura, T. \& Tsutsui, T. Synthesis and characterization of oligo (9,9-dihexyl-2,7-fluorene ethynylene)s: for application as blue light-emitting diode. Org. Lett. 3, 2005-2007 (2001).

35 Weber, S. K., Galbrecht, F. \& Scherf, U. Preferential oxidative addition in Suzuk cross-coupling reactions across one fluorene unit. Org. Lett. 8, 4039-4041 (2006).

36 Ju, J. U., Chung, D. S., Kim, S. O., Jung, S. O., Park, C. E., Kim, Y.- H. \& Kwon, S.- K. Synthesis and characterization of a new ethynyl-linked alternating anthracene/fluorene copolymer for organic thin film transistor. J. Polym. Sci., Part A: Polym. Chem. 47, 1609-1616 (2009).

37 Sonogashira, K. in Handbook of Organopalladium Chemistry for Organic Synthesis (ed. Negishi, E.) 493-529 (Wiley-VCH, New York, 2002).

38 McWilliams, K. \& Kelly, J. W. Synthesis and conformational preferences of a potential $\beta$-sheet nucleator based on the 9,9-dimethylxanthene skeleton. J. Org. Chem. 61, 7408-7414 (1996).

39 Pommerehne, J., Vestweber, H., Guss, W., Mahrt, R. F., Bässler, H., Porsch, M. \& Daub, J. Efficient two layer LEDs on a polymer blend basis. Adv. Mater. 7, 551-554 (1995).

Supplementary Information accompanies the paper on Polymer Journal website (http://www.nature.com/pj) 